\title{
Hospital location-allocation in Shiraz using Geographical Information System (GIS)
}

\author{
Fatemeh Rahimi, ${ }^{1}$ Ali Goli, ${ }^{2}$ and Rita Rezaee ${ }^{3,4,{ }^{*}}$ \\ ${ }^{1}$ M.Sc, Student Research Committee, Shiraz University of Medical Sciences, Shiraz, Iran \\ ${ }^{2} \mathrm{Ph} . \mathrm{D}$, Associate Professor in Regional Planning, Department of Sociology and Social Planning, Shiraz University, Shiraz, Iran \\ ${ }^{3}$ Ph.D, Health Human Resources Research Center, School of Management \& Information Sciences, Shiraz University of Medical Sciences, Shiraz, Iran \\ ${ }^{4}$ Quality Improvement in Clinical Education Research center, Shiraz University of Medical Sciences, Shiraz, Iran \\ "Corresponding author: Rita Rezaee, Ph.D, Health Human Resources Research Center, School of Management and Information Sciences, Shiraz University of Medical Sciences, \\ Shiraz, Iran. Tel: +98-7132340783, E-mail: rita_rezaee@yahoo.com
}

Received 2016 December 10; Revised 2017 March 14; Accepted 2017 May 15.

\begin{abstract}
Background: Hospitals are one of the most important health facilities in every society. Therefore, these facilities should be located in a rational manner. The present study aims to 1) select optimal locations for establishing new hospitals in Shiraz and 2) assess the location of the existing hospitals in Shiraz using the geographical information system (GIS).

Methods: At first, the hospital location allocation criteria were identified through reviewing the literature. Then, the criteria were entered into a questionnaire, which was completed by experts based on analytic hierarchy process (AHP). Afterwards, spatial raster layers of all the criteria were created in the Arc GIS 10.3 software. Then, in order to select optimal locations for hospitals, weights of the criteria were calculated based on AHP in Arc GIS and the weights were exerted on the relevant spatial created layers. Combination of the layers was presented on a map. After evaluating the 33 existing hospitals' locations based on the map, the areas located in standard hospital service areas $(1500 \mathrm{~m})$ were erased from the map in order to exclude the served areas.

Results: The results revealed that 'proximity to the main roads' was the most important criterion amongst the whole applied criteria for selecting hospital location. This study also presented 15 land parcels, located in northern part of the city, as the best lands for constructing new hospitals. Besides, according the applied criteria in this study, none of the 33 existing hospitals were located in the appropriate locations.

Conclusions: Considering the obtained pattern of the existing hospitals' locations, in most of the cases, the existing location is not good and the future hospitals must be located in more appropriate locations. The results of this study can be useful for health policymakers to select the most suitable locations for constructing new hospitals in future.
\end{abstract}

Keywords: Geographical Information System, Hospital, Health, Location-Allocation, Site selection, Spatial-AHP

\section{Background}

Healthcare managers are commonly faced with various problems. In most of these problems, they are subjected to multiple conflicting criterias that should be considered in the decision making process. Selecting the optimal location for establishing new hospitals, known as hospital location-allocation, is one of these multi criteria decision making (MCDM) problems. In such problems, considering just only 1 criterion will result in ignoring other criteria. For instance, considering minimizing the total cost and maximizing the total accessibility to healthcare facilities as 2 conflicting criterias, minimizing the total cost requires reduction of the number of healthcare facilities, while maximizing the total accessibility to healthcare facilities requires increasing the number of these facilities (1). Furthermore, every facility should be compatible with other neighboring facilities and land-uses. For instance, constructing a hospital in a certain location may lead to improvement of accessibility, while the location may be lo- cated in a place neighboring incompatible land-uses. Such conflicts should be considered in problem solving. In general, solving facility location allocation problems as a complex kind of spatial problems requires utilization of spatial analysis methods (2). Spatial analytic hierarchy process (SAHP) is a spatial analysis technique that combines AHP, which is an MCDM technique, with spatial data in Geographical Information System (GIS) environment (3). The combination of GIS and AHP has been used in various location allocation problems including healthcare centers location allocation (4), landfill site selection (5-7), Dam site selection (8), etc.

Up to now, different studies have been conducted in order to assess the location of healthcare facilities, such as hospitals. Some of these studies have concentrated on assessing the location of the existing hospitals in a certain area. On the other hand, some other studies have focused on allocating optimal locations for constructing new hospitals. In the latter mentioned type of studies, some re- 
searchers have considered only 1 criterion in their decisions, while other researchers $(9,10)$ have paid attention to multiple criteria's.

\subsection{Study Area}

Shiraz, the capital of Fars province, is one of the most populous cities in Iran (11). Shiraz is the most developed city in the south of Iran. Although the southern parts of Iran are rich in oil, they are amongst the deprived parts of the country in terms of health enjoyment. Shiraz is known as the medical tourism pole south of the countr, and many patients, especially those from southern parts of Iran and foreign countries allocated around the Persian gulf, travel to Shiraz annually in order to receive healthcare services (12). Regarding the population growth in Shiraz and the importance of medical tourism in Iran's health programs, it is essential to improve the quality of the existing healthcare services and establish new hospitals. Also, it is important to note that in terms of geography, Shiraz is surrounded by mountains and it is not possible to expand the city's domain. Considering this limitation, health policymakers should select optimum locations for establishing new hospitals in the existing space. Therefore, the present study aims to 1) select optimal locations for establishing new hospitals in Shiraz and 2) assess the location of the existing hospitals in Shiraz using GIS.

\section{Methods}

There are 2 approaches to integrate MCDM techniques with spatial data in GIS. In the first method, multi criteria evaluations (MCE) are carried out in a stand-alone computer software and the results are sent to GIS using a file exchange mechanism. In the second method, MCE functions that are fully integrated into GIS can be used (13). In this study, the latter method was employed.

\subsection{SAHP}

SAHP, as a technique that combines AHP with spatial data in GIS environment, has 4 main steps as follows:

Step 1: Identifying the criteria, which decision makers are subjected to.

Step 2: Structuring the criteria in a hierarchical framework (including goal, criteria, and sub-criteria).

Step 3: Calculating the weights of the criteria and subcriteria regarding the decision hierarchy.

Step 4: Ranking the spatial raster or polygons according to the obtained index.

Steps 1 - 3 are based on AHP developed by Saaty $(14,15)$. In AHP, the criteria should first be identified. Then, the decision criteria should be broken down in form of a hierarchy.
After all, a pairwise comparison should be made between the elements of hierarchy in each level based on Saaty's scale (Table 1).

Table 1. Saaty's 9-Point Scale

\begin{tabular}{lc}
\hline Intensity of Importance & Definition \\
\hline $\mathbf{1}$ & Equal importance \\
\hline $\mathbf{3}$ & Moderate importance \\
$\mathbf{5}$ & Strong importance \\
$\mathbf{7}$ & Very strong or demonstrated importance \\
$\mathbf{9}$ & Extreme importance \\
$\mathbf{2 , 4 , 6 , \text { and } \mathbf { 8 }}$ & Intermediate values \\
\hline
\end{tabular}

In AHP, pairwise comparisons aim at the calculation of the criteria's weights and priorities. To calculate the weights, the eigenvector method (Equation 1) was proposed by Saaty:

$\mathrm{AW}=\lambda_{\max } \mathrm{W}$

Where $A$ is the $n$ by $n$ comparison matrix, $n$ is the number of items being compared in the matrix, and $\lambda_{\max }$ is the largest eigenvalue of $\mathrm{A}$.

$W=\lim _{k \rightarrow \infty} \frac{A^{k} e^{T}}{e^{T} A_{e}^{k}}$

Where $\mathrm{e}^{\mathrm{T}}$ is the transpose of $\mathrm{e}=(1,1,1, \ldots, 1)$.

Decision makers' subjective judgments in AHP can lead to inconsistency in the comparison matrices (16). Yet, the quality of a decision can be improved by identifying the inconsistencies (17). If consistency ratio (CR) is less than 0.1, estimation of $\mathrm{W}$ will be acceptable; otherwise, the inconsistency must be improved (18) by revising judgments.

$\mathrm{CR}=\mathrm{CI} / \mathrm{RI}$

$C I=\frac{\lambda \max -n}{n-1}$

Where $\mathrm{RI}$ is the average consistency index for random matrices and $\mathrm{Cl}$ is the consistency index.

After all, the priorities of the criteria and sub-criteria are determined based on their weights.

In this study, SAHP-based evaluation was performed via the following steps:

Step 1: In order to find the hospital location allocation criteria, an electronic database search was conducted via PubMed, ScienceDirect, and Google Scholar databases. The applied keywords were 'location allocation', 'site selection', 'hospital', 'Geographical Information System', and 'healthcare organizations'. There was no limitation in terms of applied criteria or techniques in the search strategy. However, it was limited to studies published in 2011 - 
2015. Review of the literature revealed 9 criteria, including population density, fair distribution of hospitals all over the city, fast and easy accessibility, proximity to the main roads, being far from airport, not being located on the river path, being far from industrial centers, proximity to fire stations, and land area.

Step 2: The criteria were classified into 5 main criteria and their sub-criteria.

Step 3: All the criteria were entered into a questionnaire and 18 experts were asked to complete the questionnaire. AHP is a non-statistically based process, and was originally developed to help a single decision maker in the decision making process. Therefore, it can be implemented with a sample size including just a single expert or more (19). In this study, all of the experts who had experience in hospital development (at least 2 years) in the vice-chancellery for resource development and the vicechancellery for treatment at Shiraz University of Medical Sciences were asked to complete the questionnaires. The total of experts was 18 people, including health managers, urban planners, community medicine experts, and technical team of Shiraz University of Medical Science who take part in selecting hospital locations (Table 2). The aim of this questionnaire was to determine the relative importance of the mentioned criteria.

Table 2. Characteristics of the Experts

\begin{tabular}{l|c|c}
\hline \multirow{2}{*}{ Specialty } & Number of Experts & Academic Degree \\
\hline \multirow{2}{*}{ Health manager } & 1 & MPH \\
\cline { 2 - 3 } & 4 & PHD \\
\cline { 2 - 3 } & 1 & M.Sc. \\
\cline { 2 - 3 } & 1 & B.Sc. \\
\hline Urban planner & 5 & PHD \\
\hline $\begin{array}{l}\text { community medicine } \\
\text { experts }\end{array}$ & 1 & PHD \\
\hline $\begin{array}{l}\text { Technical team of Shiraz } \\
\begin{array}{l}\text { University of Medical } \\
\text { Sciences }\end{array}\end{array}$ & 1 & M.Sc. \\
\hline
\end{tabular}

Step 4: The spatial raster layers of all 9 criteria were created in GIS as follows:

1. Population density: Population density was calculated by dividing the number of people who settled in every census unit by the area of that unit. Accordingly, more populated areas got higher priority compared other areas.

2. Fair distribution of hospitals all over the city: In order to determine how the hospitals were distributed in the city, the distance of every land-use from the nearest hospital was calculated. To construct new hospitals, the land- uses that were located in further distances got higher priority compared to closer land-uses.

3. Fast and easy accessibility: In order to determine the accessibility level, the distance of every residential landuse from the nearest hospital was calculated. Accordingly, people who lived in closer distances had better accessibility. Therefore, to construct new hospitals, they got a lower priority compared to others.

4. Proximity to the main roads: at first, the roads whose width was more than $30 \mathrm{~m}$ were selected as the main roads. Then, the distance of every residential land-use from the selected roads was calculated. The land-uses located in closer distances from the main roads got priority over other landuses.

5. Being far from airport: the distance of every residential land-use from Shiraz airport was calculated. The landuses located in closer distances from the airport got lower priority compared to other land-uses.

6. Not being located on the river path: the distance of every residential land-use from Shiraz river (Saheli River) was calculated. The land-uses located in closer distances from the river got lower priority compared to other landuses.

7. Being far from industrial centers: the distance of every residential land-use from industrial centers was calculated. The land-uses located in closer distances from the industrial centers got lower priority compared to other landuses.

8. Proximity to fire stations: the distance of every residential land-use from Shiraz fire stations was calculated. The land-uses located in closer distances from the fire stations got higher priority compared to other land-uses.

9. Land area: according to the standards of Iran's ministry of health, the least appropriate area for a hospital with 32 beds is 5000. Therefore, the lands with areas < 5000 got lower priority.

Then, the results of pairwise comparisons were entered into AHP extension tools of Arc GIS10.3. After calculating the weights and CRs, the weights were exerted on the 9 layers and the layers were combined. The result of this combination was a unique raster layer. The final layer was classified into 5 classes based on quintile intervals. Therefore, the Shiraz area was divided into 5 groups, including areas with very low, low, moderate, high, and very high potentials for constructing hospitals. Afterwards, the obtained map was overlaid with the spatial layer of the existing hospitals' locations. Accordingly, the location of the Shiraz hospitals (33 hospitals) was assessed in terms of suitability based on the applied criteria. After all, in order to exclude the served areas, the areas that were located in standard hospital service areas (1500 $\mathrm{m}$ ) were erased from the obtained layer using network analysis and erase tools in 
Arc GIS. Network analysis is a spatial analysis technique to calculate distances between 2 points using network data, such as roads network. The final result was another map that indicated the priority of Shiraz deprived areas for establishing new hospitals. In the following, among the most appropriate areas, the most appropriate land parcels were selected based on 4 main characteristics, including: a) earth's tilt $<0.05$, b) being non-residential, c) land area $>5000$, and d) located in proximity to the main roads.

It should be mention that the applied questionnaire in this study was approved by Shiraz University of Medical Sciences in terms of ethics. Furthermore, the experts had the option to fill the questionnaires or not. In addition, confidentiality and privacy of information was maintained in all steps of this study. Besides, an ethical commitment was given to the Municipality Organization of Shiraz for giving them a copy of results.

\section{Results}

Review of the literature revealed 9 criteria, including population density (20,21), fair distribution of hospitals all over the city (21), fast and easy accessibility (22), proximity to the main roads (21), being far from airport, not being located on the river path (23), being far from industrial centers $(4,23)$, proximity to fire stations $(24,25)$, and land area (26). The results of calculating the criteria's weights have been presented in Table 3. As the table depicts, the calculated CRs for all created matrices were less than 0.1. Therefore, there was no need for revising the questionnaires by the experts (18). Moreover, 'Proximity to the main roads' (0.2234) got the first priority.

The results of prioritizing all areas of the city in terms of their potentials for constructing new hospitals have been presented in Map 1-A. In addition, the results of prioritizing limited access areas of the city in terms of their potentials for constructing new hospitals have been presented in Map 1-B.

Among the most appropriate areas (areas with very high or high potential), 159 land parcels were identified as the appropriate lands (Map 2-A). The area of the appropriate lands were between the ranges of 5005.8 to 559521.4. Of these, 15 land parcels were located in the areas with very high potential. Therefore, they were determined as the best lands. The 15 best lands were located in the northern part of the city (presented in pink, Map 2-B).

The results of overlaying the spatial layer indicating the existing hospitals' locations with Map 1-A have been presented in Table 4 . The results revealed that with respect to the applied criteria, none of the existing hospitals were located in areas with high or very high potentials (Figures 1 and 2).

\section{Discussion}

Managing healthcare resources in an appropriate and efficient way, can improve access to health services and reduce health care costs (27). Hospitals, as one of the most important organizations, play a vital role for preserving and promoting individuals' health in every country. Respecting this vital role, it is so important to select a proper site for constructing new hospitals. The lack of comprehensive planning and management in selecting appropriate location for hospitals can lead to unpleasant consequences such as reducing access to hospitals, enhancing the time of rescue, enhancement in expenses for both governments and patients, as well as reducing patient satisfaction. Therefore, paying attention to select proper locations for hospitals based on scientific principles is a necessary task for policymakers. Unfortunately, in most of the cases, especially in developing countries, hospital site selection is not based on scientific criteria. Iran is not excluded from this situation. Shiraz is one of the biggest cities of Iran. The ever increasing population of Shiraz amplifies the demand for establishing new hospitals. However, up to now, no comprehensive studies have been conducted on different aspects of hospital location selection in Shiraz. One of the bold attributes of the present study was focusing on different aspects that should be considered in selecting appropriate sites, such as population characteristics, accessibility, equity in distribution, compatibility and incompatibility with other land-uses, as well as quantitative characteristics such as land area. Based on the results of the AHP analysis, 'Proximity to the main roads' (0.2234) got the first priority. This was followed by 'population density' (0.1986), 'proximity to fire stations' (0.1710), 'land area' (0.1395), 'fair distribution all over the city' (0.0910), 'not being located on the river path' (0.0691), 'fast and easy accessibility' (0.0440), 'being far from airport' (0.0406), and 'being far from industrial centers' (0.0226) (Table 3). The results also revealed that southwestern, western, and northwestern areas of Shiraz had more appropriate potential for new hospitals compared to other parts of the city. Accordingly, the best locations were in zones 2 and 10 (locations with very high potential, presented in blue in Map 1-B). In addition, the majority of highly potential areas were located in zone 10 followed by zone 9 (presented in gray in Map 1-B). On the other hand, the majority of areas with very low or low potentials (presented in dark brown and brown, respectively in Map 1-B) were located in zones 1, 3, 6 , and 7. Finally, the majority of areas with moderate potential (presented in yellow in Map 1-B) were dispersed in southern and western parts of the city. In the following, this study presented 15 land parcels that are completely in accordance with the applied criteria in this study (Map 
Table 3. Hospital Location Allocation Criteria's Weights Based on AHP

\begin{tabular}{|c|c|c|c|c|c|c|}
\hline Main Criteria & Criteria's Weights & CR & Sub-Criteria & $\begin{array}{l}\text { Sub-Criteria's } \\
\text { Weights }\end{array}$ & Synthetic Weights & Priority \\
\hline Population & 0.1986 & & Population density & 0.1986 & 0.1986 & 2 \\
\hline \multirow{2}{*}{ Accessibility } & \multirow{2}{*}{0.1351} & \multirow{2}{*}{0} & $\begin{array}{l}\text { Fair distribution all } \\
\text { over the city }\end{array}$ & 0.6743 & 0.0910 & 5 \\
\hline & & & $\begin{array}{l}\text { Fast and easy } \\
\text { accessibility }\end{array}$ & 0.3257 & 0.0440 & 7 \\
\hline Road network & 0.2234 & & $\begin{array}{l}\text { Proximity to the main } \\
\text { roads }\end{array}$ & 0.2234 & 0.2234 & 1 \\
\hline \multirow{3}{*}{ Incompatibility } & \multirow{3}{*}{0.1324} & \multirow{3}{*}{0.0128} & Being far from airport & 0.307 & 0.0406 & 8 \\
\hline & & & $\begin{array}{l}\text { Not being located on } \\
\text { the river path }\end{array}$ & 0.5221 & 0.0691 & 6 \\
\hline & & & $\begin{array}{l}\text { Being far from } \\
\text { industrial centers }\end{array}$ & 0.1709 & 0.0226 & 9 \\
\hline Compatibility & 0.1710 & & $\begin{array}{l}\text { Proximity to fire } \\
\text { stations }\end{array}$ & 0.1710 & 0.1710 & 3 \\
\hline Land specifications & 0.1395 & & Area & 0.1395 & 0.1395 & 4 \\
\hline
\end{tabular}

${ }^{\mathrm{a}}$ Consistency Ratio $(\mathrm{CR})=0$.

Table 4. Suitability Level of Shiraz Hospitals' Locations Based on the Applied Criteria

\begin{tabular}{|c|c|c|c|c|c|}
\hline Hospital ID & Hospital Ownership & Location Suitability & Hospital ID & Hospital Ownership & Location Suitability \\
\hline $\mathbf{1}$ & Governmental & Low & 18 & Non-Governmental & Very low \\
\hline 2 & Governmental & Low & 19 & Non-Governmental & Low \\
\hline 3 & Non-Governmental & Very low & 20 & Non-Governmental & Very low \\
\hline 4 & Governmental & Very low & 21 & Governmental & Very low \\
\hline 6 & Non-Governmental & Moderate & 23 & Governmental & Low \\
\hline 7 & Non-Governmental & Very low & 24 & Governmental & Low \\
\hline 8 & Governmental & Moderate & 25 & Non-Governmental & Very low \\
\hline 9 & Governmental & Very low & 26 & Non-Governmental & Low \\
\hline 10 & Governmental & Low & 27 & Governmental & Low \\
\hline 12 & Governmental & Low & 29 & Non-Governmental & Low \\
\hline 13 & Non-Governmental & Low & 30 & Governmental & Low \\
\hline 14 & Governmental & Low & 31 & Non-Governmental & Low \\
\hline 15 & Governmental & Very low & 32 & Governmental & Very low \\
\hline 16 & Non-Governmental & Low & 33 & Governmental & Low \\
\hline 17 & Non-Governmental & Low & & & \\
\hline
\end{tabular}

2). All parcels were located in in northern part of the city. In a previous study carried out in zone 5 in Shiraz (26), researchers considered 4 criteria, namely distance from other hospitals, population density, distance from arterial roads, and location size. These 4 criteria were a subdivision of the applied criteria in our study. In another study performed in Dhaka (23), researcher employed 5 criteria; i.e., distance from existing hospitals, main roads, industries, educational institutions, and water bodies. Among these criteria, distance from existing hospitals, main roads, in- 

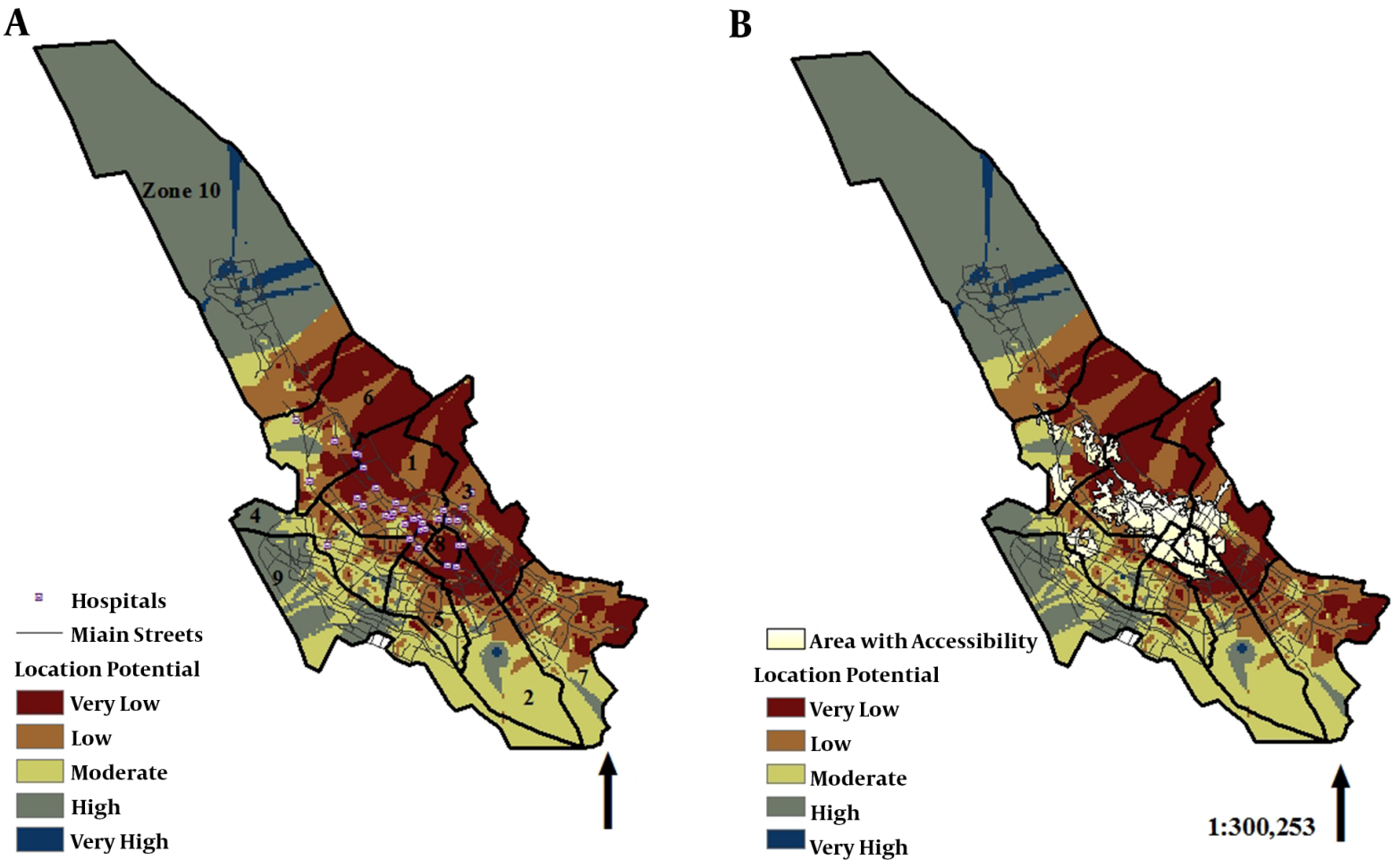

Figure 1. Suitability Level of Shiraz Areas for Establishing Hospitals Based on the Applied Criteria

dustrial centers, and water bodies were the same as those applied in our study. Another study carried out in Ardabil (25) considered 13 criteria. Among those criteria, 6 (distance from fire stations, existing hospitals, main roads, and industrial centers, population density, and accessibility (distance from residential land-uses)) were similar to the applied criteria in the present study. In another study conducted in Benghazi to select the optimal location for new hospitals (28), 3 of the used criteria; i.e., access to road network, location size, and fair distribution in different geographical regions, were consistent with those utilized in the current study.

The suitability level of the existing hospitals' locations was also taken into account in the present study. The results revealed that $93.75 \%$ of the existing hospitals were located in areas with inappropriate potential and 6.25\% were located in areas with moderate potential. However, none of the hospitals were located in areas with appropriate potentials (Table 4). Situation of existing hospitals has been assessed by various researchers in different countries. Most of these studies, such as those conducted in Michigan, New Zealand, and Ireland (29-31), have only focused on population accessibility and equity in access. However, in addition to accessibility, the present study researchers considered other important criteria in assessing hospitals location.

It can be noted that in most of the cases, the hospital lands in Shiraz were an endowment. In addition, shifting existing hospitals' locations to other places is not cost effective. Therefore, the present study recommends to policymakers to pay more attention to necessary actions for preparing hospitals' location in future. Overall, the results of the current study can help healthcare policymakers make more efficient decisions. Considering the fact that none of the existing hospitals were located in lands with appropriate potential, policymakers are required to pay special attention to these locations and make essential measures. The present study recommends to policymakers to give priority to establishing new hospitals in areas without standard accessibility over areas with standard accessibility based on Map 1-B. It is also crucial to use scientific hospital location allocation criteria and regard to their priorities based on experts' opinion. The results of this study (presented in Table 3) can help policymakers become a valuable tool. Besides, they should try to reserve areas with appropriate potential for constructing hospitals 

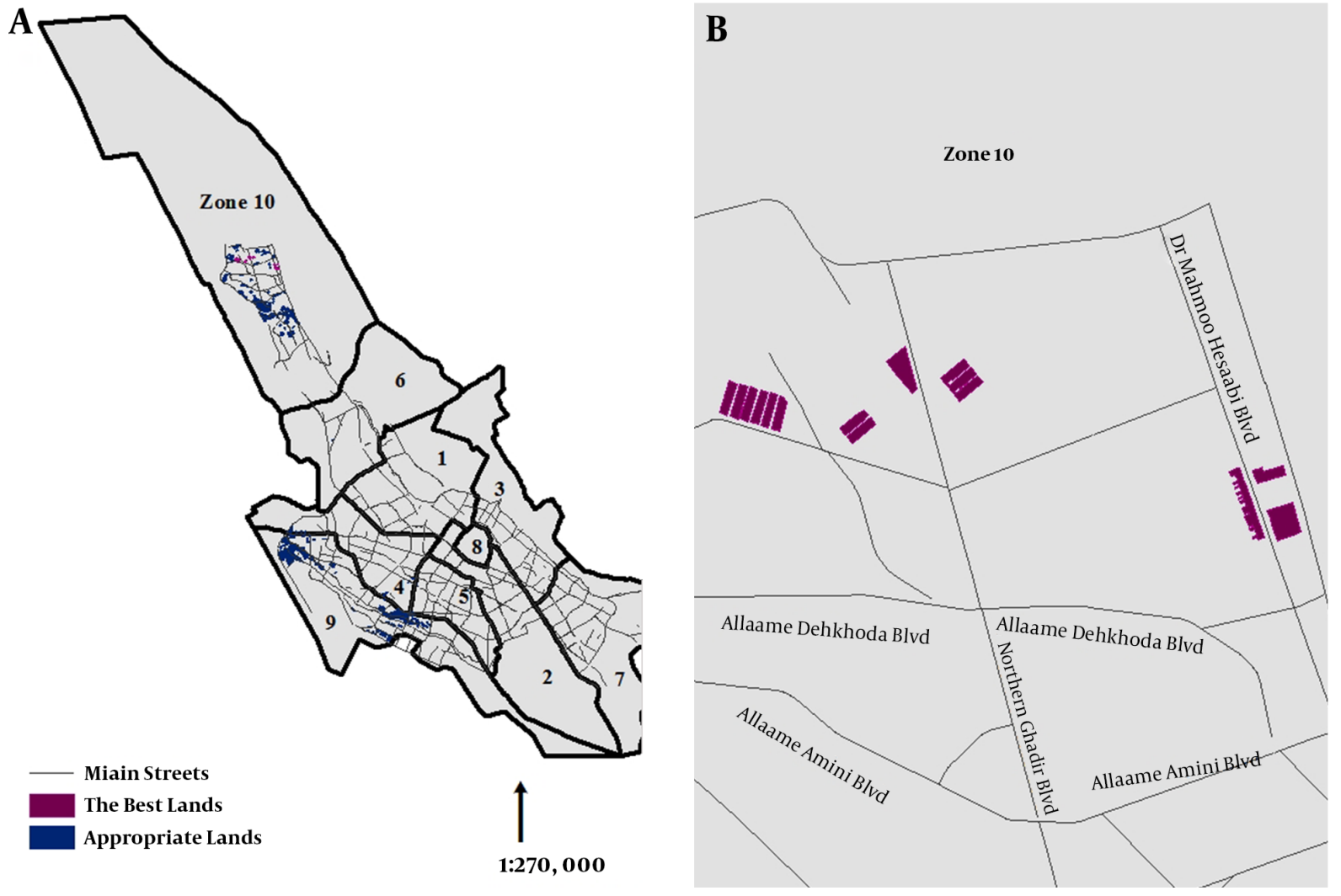

Figure 2. Appropriate Lands for Establishing Hospitals Based on the Applied Criteria

than constructing other facilities. It is also recommended to health authorities to use GIS to make sure that other health resources are spent in appropriate locations.

\subsection{Conclusions}

As already mentioned, an optimal location-allocation is a process that evaluates facilities' location in terms of various criteria. Evaluating population accessibility and compatibility of healthcare facilities with other neighboring land-uses are 2 of the most important criteria in selecting the best locations. In addition to the 2 abovementioned criteria, the present study focused on other important criteria, including population density in different areas, area of lands according the standards of Iran's ministry of health, and proximity to road networks. Better accessibility can save patients' traveling time to hospitals in emergency situations, reduce traveling costs, and improve equity in health. Indeed, paying attention to compatibility criteria can result in increasing patient satisfaction due to elimination of the destructive effects of facilities, such as noise pollution.

\section{Acknowledgments}

This manuscript was extracted from Fatemeh Rahimi's M.Sc. thesis in medical informatics (Project No. 94-0107-10074), which was financially supported by the vicechancellery of Research and Technology at Shiraz University of Medical Sciences, Shiraz, Iran. Hereby, the authors would like to thank the center for development of clinical research of Nemazee hospital for their cooperation in the research. We would also like to thank Ms. A. Keivanshekouh at the research improvement center of Shiraz University of Medical Sciences for improving the use of English in the manuscript as well as the Municipality Organization of Shiraz for cooperating in data gathering.

\section{Footnotes}

Authors' Contribution: Study concept and design: Ali Goli; acquisition of data: Fatemeh Rahimi; analysis and interpretation of data: Fatemeh Rahimi and Ali Goli; drafting the manuscript: Fatemeh Rahimi and Rita Rezaee; study supervision: Rita Rezaee and Ali Goli. 
Funding/Support: This study was supported by the vicechancellery of research and technology at Shiraz University of Medical Sciences, Shiraz, Iran.

Conflict of Interest: None declared.

\section{References}

1. Zhang W, Cao K, Liu S, Huang B. A multi-objective optimization approach for health-care facility location-allocation problems in highly developed cities such as Hong Kong. Comput Environ Urban Systems. 2016;59:220-30. doi: 10.1016/j.compenvurbsys.2016.07.001.

2. Carver SJ. Integrating multi-criteria evaluation with geographical information systems. Int J Geographic Inf Systems. 1991;5(3):321-39. doi: 10.1080/02693799108927858.

3. Zarkesh MK, editor. Decision support system for floodwater spreading site selection in Iran. 2005; ITC.

4. Sahraeian Z, Zangiabadi A, Khosravi F. Spatial Analysis and Site Selection of Health Medical and Hospital Centers Using (GIS)(Case Study: Jahrom City).;2013.

5. Uyan M. MSW landfill site selection by combining AHP with GIS for Konya, Turkey. Environ Earth Sci. 2013;71(4):1629-39. doi: 10.1007/s12665-013-2567-9.

6. Kumar S, Hassan MI. Selection of a Landfill Site for Solid Waste Management: An Application of AHP and Spatial Analyst Tool. J Indian Soc Remote Sensing. 2012;41(1):45-56. doi:10.1007/s12524-011-0161-8.

7. Rahmat ZG, Niri MV, Alavi N, Goudarzi G, Babaei AA, Baboli Z, et al. Landfill site selection using GIS and AHP: a case study: Behbahan, Iran. KSCE J Civil Engin. 2017;21(1):111-8.

8. Dai X. Dam site selection using an integrated method of AHP and GIS for decision making support in Bortala, Northwest China. Lund University; 2016.

9. Wu CR, Lin CT, Chen HC. Optimal selection of location for Taiwanese hospitals to ensure a competitive advantage by using the analytic hierarchy process and sensitivity analysis. Building Environ. 2007;42(3):1431-44. doi:10.1016/j.buildenv.2005.12.016.

10. Vahidnia $\mathrm{MH}$, Alesheikh AA, Alimohammadi A. Hospital site selection using fuzzy AHP and its derivatives. J Environ Manage. 2009;90(10):3048-56. doi: 10.1016/j.jenvman.2009.04.010. [PubMed: 19477577]

11. Iran SCo . Census report 2011. Available from: https://www.amar.org. ir/Portals/2/pdf/jamiat_shahrestan_keshvar3.pdf.

12. Science IAoSUoM . Medical tourism 2016. Available from: http://ia. sums.ac.ir/fa/HealthTourism/index.html\#.

13. Jankowski P. Integrating geographical information systems and multiple criteria decision-making methods. Int J Geographic Inf Systems. 1995;9(3):251-73. doi: 10.1080/02693799508902036.

14. Saaty TL. The Analytic (Hierarchy) Process. ; 1980.
15. Saaty TL. Decision making with the analytic hierarchy process. Int Serv Sci. 2008;1(1):83-98.

16. Saaty TL. Decision-making with the AHP: Why is the principal eigenvector necessary. EurJ Operat Res. 2003;145(1):85-91. doi:10.1016/s03772217(02)00227-8.

17. Saaty TL. Highlights and critical points in the theory and application of the Analytic Hierarchy Process. Eur J Operat Res. 1994;74(3):426-47. doi: 10.1016/0377-2217(94)90222-4.

18. Saaty TL, Wong MM. Projecting average family size in rural India by the analytic hierarchy process. J Math Sociol. 1983;9(3):181-209. doi: 10.1080/0022250X.1983.9989942. [PubMed: 12312762].

19. Duke JM, Aull-Hyde R. Identifying public preferences for land preservation using the analytic hierarchy process. Ecol Econ. 2002;42(12):131-45. doi:10.1016/s0921-8009(02)00053-8.

20. Wissem E, Ahmed F, Mounir B. Multicriteria method for a site selection of a new hospital in Sfax. Logistics (LOGISTIQUA). 4th International Conference. IEEE;

21. Wu J, Zhou L. GIS-Based Multi-Criteria Analysis for Hostital Selection in Haidian District of Beijing. ; 2012.

22. Ahadnejad M, Ghaderi H, Hadian M, Haghighatfard P, Darvishi B, Haghighatfard E, et al. Location Allocation of Health Care Centers Using Geographical Information System: Region 11 of Tehran.J Fasa Univ Med Sci. 2015;4(4)

23. Sharmin N, Neema MN. A GIS-based multi-criteria analysis to site appropriate locations of hospitals in Dhaka City. Hospital. 2013;8:0-37.

24. Mikaniki J, Sadeghi H. Location of medical-health centers (hospitals) in Birjand city through a combination of network analysis process (ANP) and paired comparisons by GIS. Environmental Based Territoria Planning. 2013;15(9):121-42.

25. Veysi Nab F, Babaei Agdam F, Sadeghieh S, Asadi G. Locating hospitals using weighted linear combination model in GIS environment in Ardabil City. J Health. 2015;6(1):43-56.

26. Soltani A, Marandi IZ. Hospital site selection using two-stage fuzzy multi-criteria decision making process. Journal of Urban and Environmental Engineering. 2011;5(1)

27. Ravangard R, Hatam N, Teimourizad A, Jafari A. Factors affecting the technical efficiency of health systems: A case study of Economic Cooperation Organization (ECO) countries (2004-10). Int J Health Policy Manag. 2014;3(2):63-9.

28. Ibrahim M A, Mohamed A. Hospital Site Selection in Benghazi City in Libya. International Conference on Industrial Engineering and Operations Management. 2012;1(1):399-409.

29. Brabyn L, Skelly C. Modeling population access to New Zealand public hospitals. Int J Health Geogr. 2002;1(1):3. [PubMed: 12459048].

30. Kalogirou S, Foley R. Health, Place and Hanly: modelling accessibility to hospitals in Ireland. Irish Geograph. 2006;39(1):52-68.

31. Varnakovida P, Messina P. Hospital site selection analysis. Proceedings of the IMAGIN annual Conference. Citeseer; 